\title{
Comparative analysis of the burnout syndrome among secondary and higher education teachers
}

\author{
A.V. Speranskaya ${ }^{1 *}$, S.A. Prokopyeva ${ }^{2}$, and M.M. Popovich ${ }^{3}$ \\ 1 The Vologda Institute of Law and Economics of the Federal Penitentiary Service of Russia, \\ Vologda, Russia \\ ${ }^{2}$ The Vologda Institute of Law and Economics of the Federal Penitentiary Service of Russia, \\ Vologda, Russia \\ ${ }^{3}$ The North-Western Institute (branch) Kutafin Moscow state law University (MSLA), Vologda, \\ Russia
}

\begin{abstract}
The features of the teachers' burnout syndrome that depends on their place of work are compared. The organizational factor is considered to be the reason that contributes to the formation of this phenomenon. It is stated that secondary education teachers are more susceptible to the development of emotional burnout in comparison with higher education teachers who have the same work experience. Secondary education teachers are characterized by the formation of a phase of resistance which is clearly revealed through an inadequate emotional response to problems that arise in their professional activity. In hard situations they prefer to address to a psychologist's for help to solve their problems and do not address to the colleagues and management for the fear of showing their incompetence. In contrast, the higher education teachers seek help from colleagues, management and the Internet, so, they do not have feelings of helplessness. It is necessary to provide psychological support to the teachers taking into account organizational factors.
\end{abstract}

\section{A problem statement}

Among the variety of professions in the world the profession of a teacher takes a special place. This profession is very multitasking. A teacher of any level of education should keep accounting and reporting records both in paper and electronic, for example, fill in paper and electronic gradebooks, lead groups in social networks with parents, students and colleagues, develop and conduct classes, including using various technical equipment, make educational and methodological sets for academic disciplines. The higher the level of education, the more types of work the teacher performs. Besides higher education teachers are also responsible for conducting research work. The teacher has to report within the established time limit for all types of work.

\footnotetext{
*Corresponding author: prof-ped.gpa@mail.ru
} 
Among other things, the teacher is to meet increased demands - he or she must be sociable, patient, persistent, intelligent, erudite, fair, attentive, reserved, creative, with a sense of humor, etc. The teacher constantly interacts with people of different ages and social status. These contacts are long-term and forced. The teacher is responsible for the children's life and health. However, there is an inverse dependence here - the higher the level of education, the less time and neuropsychiatric costs the teacher bears for students' health. All mentioned above allows us to consider the teacher's profession as stressful. It is not surprising that it is in this profession that emotional burnout among teachers is mostly common.

\subsection{The objective of the work}

Though this phenomenon has been described for quite a long period of time, there is still no unanimous approach to its understanding in the scientific domestic and foreign literature. So, some researchers classify emotional burnout as professional destruction $[1,2]$, others refer it to unfavorable functional states [3,4], some believe that this is an indicator of depression [5], some researchers consider emotional burnout as a clinical syndrome with neurotic features $[6,7]$, some researchers define this phenomenon as a process of helping others which under the influence of stress factors causes the teacher's problems with psychological and physiological health [8].

The researchers completely agree at the point they figure out of the negative effects of emotional burnout. The teacher who has emotional burnout demonstrates deterioration in the quality of work, dissatisfaction with both the process and the result of work, a detached position and deterioration of psychological and physical health. In addition, teachers with a developed burnout syndrome have an extremely negative impact on their students, sociopsychological climate in class and also on their colleagues [9].

Among the factors that contribute to the development of teachers' emotional burnout the greatest coverage was given to their personal characteristics. Thus, the connection between teachers' communication skills and their emotional burnout has been established [10]. At the core of the emotional part of interpersonal relations in the teacher-student system is the teachers' attitude towards students: the more negative this attitude and the inability to take an equal position with a student, the worse the communication between them. Researchers T.I. Dzhappueva and T.V. Timoshenko proved that it is irritation, indirect aggression and resentment that are most clearly revealed in teachers with the formed burnout syndrome [11]. Besides, significant differences were found in the expression of aggressive reactions that depend on the gender of teachers. Male teachers react more calmly to difficult situations than female teachers [11]. Also among the personal characteristics in the group of individual factors of the development of this syndrome there is rigidity of thinking, poorly developed creativity, unwillingness to contact not only with students but also with colleagues [12] and low emotional intelligence [13, 14]. Among the key personal characteristics which cause the development of an undesirable phenomenon, researchers point out the insufficient development of stress resistance [15]. Stress tolerance is considered to be a professional and personal quality that ensures the safety and quality of work performed by teachers even in stressful situations of their professional activities. The authors emphasize that even the availability of a well-developed stress tolerance does not guarantee the teachers' absolute protection from the burnout syndrome. It is necessary to provide psychological support to the teaching staff in order to optimize their stress tolerance and neutralize the development of emotional burnout. Working experience is not always a necessary resource to overcome professional destruction. The teachers note that their anxiety, irritability, a sense of emotional exhaustion and a lowering interest in work increase together with the growth of their teaching experience [16]. At the same time labor 
motivation also undergoes changes - from internal it turns out into external negative [17, 18]. The formation of teachers' emotional syndrome is added by the development of various diseases of psychosomatic nature [19]. Teachers begin to immerse themselves into illness because they can no longer meet the constantly rising demands and various innovations that become mandatory in the pedagogical process.

The literature review showed insufficient consideration of organizational factors in the development of teachers' emotional burnout syndrome. We are interested in the idea of comparing teachers of secondary and higher education proposed by A.S. Leonova and her supervisor L.S. Skripnichenko [20]. Despite the similarity in the professional activities of teachers working at these levels of education, there are significant differences in their work, in particular, concerning their labor organization and types of work. We decided to continue the comparative analysis in the study of emotional burnout syndrome's representation in order, firstly, to clarify the features of the formation of emotional burnout and secondly, to define additional sources of its formation or resources of its prevention or overcoming, as various proposed models of prevention are very superficial and do not take into consideration the specific features of teachers' activity in accordance with their place of work and types of students they work with.

\section{Results of the research}

The methodology of «Research of emotional burnout» (author V.V. Boyko) and a standardized interview were chosen as the main tools of the research. The research was conducted on the basis of secondary school No. 29 and Vologda State University in Vologda city. The research sample included 60 teachers from 30 to 40 years old divided into two groups in accordance with their place of work: 30 secondary education teachers and 30 higher education teachers. The samples were balanced by gender and teaching experience. The group of higher education teachers will be further referred to as EG-1, and the group of secondary education teacher - as EG-2. To process the obtained results, we used measures of the central tendency, frequency distribution and the Mann-Whitney Utest.

On the basis of the results obtained we will proceed to a detailed analysis of the components of emotional burnout among teachers of the Polytechnic University (see Table 1). So, according to the calculations, the symptoms and components (phases) of emotional burnout are within the normal distribution. Thus, we can conclude that the higher education teachers are able to cope with stress, adequately respond to various stressful factors in their professional activities and demonstrate personal interest in their work.

According to with the scales of the questionnaire, we calculated the three phases of burnout. So, the stress phase (average value is 23.6) consists of the following interrelated symptoms: «Experiencing psychotraumatic situations» (the average value is 7.8), «Dissatisfaction with oneself» (the average value is 5.5), «Anxiety» (the average value is 10.1). Analyzing the indicators of the stress phase we can definitely say that the complex of symptoms proves that this stage of burnout is not formed. Higher education teachers while performing their professional duties enjoy the work and, therefore, experience neither internal nor external stress. However, it is necessary to pay attention to the symptom of anxiety which is at the top of the standardized indicators. It can be assumed that this indicator, on the one hand, can indicate anxiety as a personal trait, and on the other hand, it can be a situational component due to anxiety and alertness of teachers caused by the testing. It should be noted that all teachers took part in the testing with interest and subsequently had a conversation on the results obtained.

The next component of emotional burnout is a phase of resistance (average value is 28.1) which includes the following interrelated symptoms: «Inadequate emotional 
response» (average value is 5.4), «The emotional and moral disorientation» (average value is 5.6), «Extending the sphere of economy resources» (average value is 4.8), «Reduction of professional duties» (average value is 10.9), «Trapped into the cage» (average value is 1.4). Attention is drawn to the symptom «Reduction of professional duties» where the value approach the level, therefore, it can be assumed that higher education teachers are on the brink of the professional crisis, when there is a declining interest in obtaining and applying new knowledge. This fact can also be explained by the students' transition to distance learning, when teachers have mostly lost direct contacts with students and taught them virtually that did not contribute to the professional development of both of them. Perhaps, higher education teachers can be characterized by an unscrupulous attitude to their official duties in some cases. This fact is confirmed indirectly by the low indicators of the "Trapped into a cage» symptom, when teachers felt free to choose alternative teaching methods and techniques as well as approaches to evaluating students. Despite of all mentioned above, the resistance phase of higher education teachers was not developed that undoubtedly indicates the adequacy of the emotional state of higher education teachers.

The third component of emotional burnout is the exhaustion phase (average value is 24.8) which includes the following complementary symptoms: «Emotional deficit» (average value is 4.6), «Emotional detachment» (average value is 5.1), «Personal detachment» (average value is 5.4) and «Psychosomatic and psych vegetative disorders» (average value is 9.7). Taking into consideration all the symptoms it can be stated that the phase has not been developed, which means that the higher education teachers do not experience emotional and personal detachment in their professional development. However, attention is paid to the symptom which approaches the level values - this is «Psychosomatic and psycho vegetative disorders». That may indicate that in case of unresolved situations in the professional sphere higher education teachers will use disease as a psychological defense. This variant is also possible as a way to avoid personal responsibility in a problem situation. It should not be forgotten that in case of distance learning the teachers take all the responsibility for the information and evaluation of students.

The next step in our research was the generalization of the results of the phases and symptoms of emotional burnout among secondary education teachers (see Table 1).

The first component of emotional burnout is the phase of tension (average value is 25.7) have received the following value among secondary education teachers: «The Experience of stressful situations» (average value is 6.9), «Dissatisfaction with themselves» (average value is 6.7), «Anxiety» (average value is 12.1). The combination of symptoms demonstrates that this phase has not been developed. However, we should pay attention to the high average value of the "Anxiety» scale. In this case anxiety may be caused by problems in the professional sphere of the teacher, for example, concerned with communication between teachers and students or parents. It is not a secret that there is a devaluation of the teacher's work at present including legal basis, when the student is always right and cannot be punished in any case. The teachers face the similar problem in the professional sphere when pedagogical development is carried out at a detriment to their own experience and at the expense of their own finances.

The phase of resistance among secondary education teachers is at the stage of its formation (average value is 61.7). This phase includes the following symptoms: «Inadequate emotional response» (average value is 17.1), «Emotional and moral disorientation» (average value is 10.6), «Expansion in the sphere of saving resources» (average value is 9.7), «Reduction of professional responsibilities» (average value is 14.9), «Trapped into a cage» (average value is 9.4). Almost all of the symptoms of the phase under study have either close value approaching the level or high ones. It should be taken into consideration that all the teachers' work is based on interpersonal interaction that can inevitably provoke complex, sometimes conflict situations where teachers may not respond 
emotionally adequately to a current situation. This reaction can be expressed in shouting, nagging, swearing both towards the students and colleagues. The results of the research also prove high value on the scale «Reduction of professional responsibilities» that indicate the lowering of teachers' professional motivation. They see no sense in further development and improvement.

The indicators of the exhaustion phases (average value is 33.2) mean that the phase has not been formed yet though some symptoms of this phase have rather high value. Symptoms of the exhaustion phase: «Emotional deficit» (average value is 6.1), «Emotional detachment» (average value is 7.6), «Personal detachment» (average value is 7.3) and «Psychosomatic and psycho vegetative disorders» (average value is 12.2). Despite of all mentioned above about the decline in professional development motivation, teachers do not work indifferently but they do work hard. But it should be noted that secondary education teachers use «immersing themselves into illness» as a psychological defense and as a result they often complain of various illnesses and are on sick leave trying to avoid personal responsibility. The results obtained again convince us that most teachers have a demonstrative personality type characterized by using the symptoms of a physical illness to attract attention.

Thus, among secondary education teachers the phases and corresponding symptoms of emotional burnout are more pronounced. So, the phase of resistance is the emerging syndrome and its characteristics are anxiety, inadequate emotional response, reduction of professional responsibilities, psychosomatic and psycho vegetative disorders.

It will be interesting to compare the features in the development of emotional burnout symptoms of teachers who work with different categories of students. The results of the comparative analysis done with the use the statistical Mann-Whitney U-test are presented in Table 1.

Table 1. Comparison of the values obtained using the method «Diagnostics of the emotional burnout level» (V.V. Boyko) in the groups of subjects under test.

\begin{tabular}{|l|l|l|l|}
\hline \multicolumn{1}{|c|}{ Scale } & EG-1 & EG-2 & $\begin{array}{l}\text { Significance of differences } \\
\text { in the Mann-Whitney U-test }\end{array}$ \\
\hline Experiencing a traumatic situations & 7.8 & 6.9 & - \\
\hline Dissatisfaction with yourself & 5.5 & 6.7 & - \\
\hline Anxiety & 10.1 & 12.1 & 0.05 \\
\hline Tension phase & 23.6 & 25.7 & 0.05 \\
\hline Unadequate emotional response & 5.4 & 17.1 & 0.01 \\
\hline Emotional and moral disorientation & 5.6 & 10.6 & 0.01 \\
\hline $\begin{array}{l}\text { Expanding the sphere of resource } \\
\text { savings }\end{array}$ & 4.8 & 9.7 & 0.01 \\
\hline $\begin{array}{l}\text { Reduction of professional } \\
\text { responsibilities }\end{array}$ & 10.9 & 14.9 & 0.01 \\
\hline «Trapped into cage» & 1.4 & 9.4 & 0.01 \\
\hline Resistance phase & 28.1 & 61.7 & 0.01 \\
\hline Emotional deficit & 4.6 & 6.1 & - \\
\hline Emotional detachment & 5.1 & 7.6 & - \\
\hline Personal detachment & 5.4 & 7.3 & - \\
\hline $\begin{array}{l}\text { Psychosomatic and psycho vegetative } \\
\text { disorders }\end{array}$ & 9.7 & 12.2 & 0.05 \\
\hline Exhaustion phases & 24.8 & 33.2 & 0.01 \\
\hline
\end{tabular}

Analyzing statistically significant differences we can state for sure that secondary education teachers show symptoms of emotional burnout to a greater extent. According to all phases, high values that confirm statistically significant differences are the stress phase $(\mathrm{p}<0.05)$, the resistance phase $(\mathrm{p}<0.01)$, the depletion phase $(\mathrm{p}<0.01)$. Fortunately, despite 
the statistically significant differences between the results in the phases of emotional burnout of tension and exhaustion, they are not formed. However, it is necessary to figure out that unlike higher education teachers secondary education teachers demonstrate high anxiety, psychosomatic and psycho vegetative disorders. It is also alarming that the phase of resistance in the context of emotional burnout is being formed among secondary education teachers. Their emotional state, inadequate response in stressful situations, lowering of pedagogical interest and motivation in professional improvement are of great concern because they can affect teachers' pedagogical activity.

Thus, it can be stated that teachers in both groups are subjected to burnout syndrome which had been confirmed by numerous and long-term studies of this phenomenon. Further, to clarify the data obtained, we conducted an interview with the teachers. The results of the interview are presented in Table 2.

Table 2. Distribution of the teachers' answers to the interview questions in both groups.

\begin{tabular}{|c|c|c|}
\hline $\begin{array}{l}\text { Number of questions and answers } \\
\end{array}$ & EG-1 & EG-2 \\
\hline \multicolumn{3}{|l|}{ 1. If you have a hard situation at work, how long do you worry about it? } \\
\hline $\begin{array}{l}\text { A) I try not to think about the situation at once, I try to distract myself } \\
\text { with other things }\end{array}$ & $64 \%$ & $54 \%$ \\
\hline B) I've been thinking about this situation all day long & $12 \%$ & $14 \%$ \\
\hline $\begin{array}{l}\text { C) I think about this situation for several days and there are thoughts } \\
\text { about quitting work }\end{array}$ & $12 \%$ & $10 \%$ \\
\hline $\begin{array}{l}\text { D) I think about it not only during working hours but also while staying at } \\
\text { home I constantly return to it in my mind, I can't sleep at night }\end{array}$ & $12 \%$ & $22 \%$ \\
\hline \multicolumn{3}{|l|}{ 1. I believe that in a hard situation at work ... helps me } \\
\hline A) Professional experience & $80 \%$ & $70 \%$ \\
\hline B) Consultations with a psychologist & - & $8 \%$ \\
\hline C) References to the management & - & - \\
\hline D) Communication with colleagues & $20 \%$ & $22 \%$ \\
\hline E) other answers & - & - \\
\hline \multicolumn{3}{|l|}{ 1. If there is a stressful situation at work, I ... } \\
\hline A) I drink coffee, alcohol, sedatives, smoke tobacco & $18 \%$ & $17 \%$ \\
\hline B) I have an insatiable feeling of hunger, cannot stop eating something & - & - \\
\hline C) I feel guilty about the situation & - & - \\
\hline D) I start disappointing with people and my work & - & $10 \%$ \\
\hline E) A stressful situation is not a problem & $50 \%$ & $73 \%$ \\
\hline F) I consult with colleagues or management & $11 \%$ & - \\
\hline G) I use the Internet to find a solution to the problem & $11 \%$ & - \\
\hline H) other options (found it difficult to answer the question) & $10 \%$ & - \\
\hline \multicolumn{3}{|l|}{ 1. What is the reason for your dissatisfaction with work? } \\
\hline A) Material and technical support & $78 \%$ & $92 \%$ \\
\hline B) The work is not properly organized & - & - \\
\hline C) Relationships with management & $10 \%$ & $8 \%$ \\
\hline D) Relationships with colleagues & $12 \%$ & - \\
\hline E) I like everything & - & - \\
\hline F) other options & - & - \\
\hline \multicolumn{3}{|l|}{ 1. Attitude towards the family } \\
\hline A) This is an additional stress & - & - \\
\hline B) I feel comfortable and calm in my family & $68 \%$ & $60 \%$ \\
\hline C) I forget about my work at home & $11 \%$ & $10 \%$ \\
\hline D) I tell my family about my problems at work & $11 \%$ & $11 \%$ \\
\hline Д) other options (I have no family) & $10 \%$ & $19 \%$ \\
\hline
\end{tabular}

The survey showed similar tendencies in the responses of teachers from both groups. The answer to the question "If you have a difficult situation at work, how long do you 
worry about it?» let us see that teachers try not to plunge immediately into an unpleasant situation to avoid inadequate reaction to it. They take time to ponder it over, understand it, and find possible solutions. This type of response also allows teachers to save their internal resources, to come to the decision with a clear and sound mind. This type of response proves that the teachers use their professional experience which is characterized by such situations and effective solution. However, we can see that secondary education teachers are less likely to do this (54\%) than higher education teachers (64\%). Almost a quarter of secondary education teachers $(22 \%)$ tend to "get stuck" on the problem situation, repeatedly replay it in their mind that can cause insomnia. The presence of insomnia can be a reliable symptom of the formation of emotional burnout. There are only $12 \%$ of higher education teachers who respond to a difficult situation that way. This category of teachers will be more vulnerable to emotional exhaustion. They need to be taught to switch their thoughts to other activities, especially at home. Meanwhile we see that a fifth of the teachers in each group cannot switch from an unexpected situation as there are answers indicating that they tend to return to this situation in mind often during the day, they have thoughts about leaving their work for being exhausted, unable to solve the problem effectively. Such teachers also need to be supported and be self-confident.

The second question of the interview, «I believe that in a difficult situation at work ... helps me» allows us to know what resources teachers use to solve the problem. The teachers chose professional experience (80\% in EG-1 and 70\% in EG-2) of all the options suggested. This indirectly confirms the indicators of the first question of the interview, in particular, the ways they respond. Indeed, the practice of solving various kinds of difficulties the teachers face in their professional activities allows them to cope with any problem that arises in the optimal time independently and effectively. A fifth of the teachers in each group (20\% in EG-1 and 22\% in EG-2) noted that colleagues help them in solving problems, it means that they are not afraid to voice out their problems and discuss solution with colleagues. Secondary education teachers ask a psychologist for help (8\%). This is quite natural as there is a psychologist or even a psychological service in every school but there is no psychological service at the university.

However, the next question «If there is a stressful situation at work, I ...» shows that in fact, the teachers address to colleagues for help much lesser (11\% in EG-1) or do not do it at all $(0 \%$ in EG-2). Thus, we can see the discrepancies in the teachers' thoughts and actions in a difficult situation. The teachers really believe that none of their colleagues will be able to help them either because of the large amount of work or because of the uniqueness of each situation, that's why they feel lonely. At the same time, a significant number of the teachers give a socially approved answer stating that «a stressful situation is not a problem» $(50 \%$ in EG - 1 and $73 \%$ in EG-2). The teachers do not want to show their incompetence among colleagues and management. A little number of higher education teachers tries to find a solution using the Internet on their own (11\%) and secondary education teachers do not use this strategy at all. This may depend on the specifics of the work they perform. Higher education teachers conduct research work and are able to find and analyze material on a given topic, and secondary education teachers do not do this type of work, so they cannot know this solution to the problem. Therefore, it is possible to show the teachers the way to use the Internet as a powerful resource to find necessary information on their problems. As secondary education teachers have few options to find help, they may sometimes feel frustrated with themselves as professionals and with others (10\%). This answer indicates a hard situation of secondary education teachers and explains the more pronounced development of the burnout syndrome. It is worth noting that teachers try to optimize their emotional state by activating or inhibiting the work of the central nervous system (18\% in EG-1 and $17 \%$ in EG-2 use coffee, tobacco, alcohol, sedatives). When developing a program for teachers who have emotional burnout, it is necessary to pay 
attention to this problem and find out whether these things really help them and in what way (how exactly it works). It is necessary to show the teachers the ways to use the techniques of self-regulation free of any substances.

During the interview the following question was asked: «What is the reason for your dissatisfaction with work?». This question is important because even an absolutely satisfied employee can be dissatisfied with some situations at work. If these dissatisfactions accumulate a critical amount, then the person ceases to experience satisfaction from work. It was revealed that the vast majority of respondents (78\% in EG-1 and $92 \%$ in EG-2) are not satisfied with the material and technical support at work. Higher education teachers are recommended to have all documents in printed form, save them in electronic form, use multimedia presentations, interactive boards, etc. However, special courses aimed at training teachers to work with this equipment are not organized anywhere and teachers have to master it on their own according to their abilities. There are also not enough personal computers for each teacher in the workplace. So they often have to do their work at home in spare time. And if the teacher knows how to use the equipment, it often turns out that this equipment is not available in the classrooms. This issue was particularly urgent during the pandemic when the educational process became distant. It turned out that many teachers did not know the way to use modern educational platforms and had problems while transferring regular classes into distant learning. Besides the material and technical aspect of work, hard relationships with managers (10\% in EG-1 and $8 \%$ in EG-2) were the source of dissatisfaction a for a few respondents. And the secondary education teachers also pointed out the relationships with colleagues as a factor of dissatisfaction (12\%). In comparison to the secondary education teachers, higher education teachers spend less time with their colleagues but it is necessary for them to solve various problems quickly, so the simultaneous presence of the teachers at school allows them to solve problems faster and effectively.

We paid attention to the family as a possible resource in prevention or correction of teachers' emotional burnout. The answers to the question "Attitude to the family» suggest that the majority of respondents consider the family as a quiet, comfortable place $(68 \%$ in EG-1 and $60 \%$ in EG-2), where you can keep away from work (11\% in EG-1 and $10 \%$ in EG-2), and besides, the teachers discuss the problems at work with their family members (11\% in both groups). The family helps them to overcome negative experiences and find optimal solutions to the problem. However, there are some teachers (10\% in EG-1 and 19\% in EG-2) who do not have a family, so, they lack the important resource to restore their strengths. This category of respondents is to see the family in their work team, otherwise they are mostly inclined to emotional burnout.

\section{Conclusions}

It is necessary to inform teachers of secondary and higher education and their management about the emotional burnout symptoms and regularly inspire their confidence in their abilities. The teachers should realize that all their difficulties at work are the opportunities for their professional development and improvement. They should be often reminded of the social significance of their profession and the pandemic has shown that the teachers are of great demand for students and their parents.

These recommendations are quite universal. The specific features in the teachers' emotional burnout formation according to their place of work should be taken into consideration while organizing psychological support. The results of the research concerning the symptoms of emotional burnout prove that it is expedient to systematize and expand the work of psychologists at schools and focus it not only on students but also on teachers. Teachers need stabilization of their emotional state, support and a goal-setting for 
further professional development, determination of their unique place in the pedagogical process and an adequately assessment by management and students. Thus, it is important for the school management to realize the need to organize and conduct training courses for teachers to master various technical devices. School psychologists should help teachers to use various opportunities to find solutions in hard situations, such as searching information on the Internet, addressing to colleagues and management for help. Round tables can be regularly held to exchange experience in solving various problems for teachers to feel the huge potential of psychological support at work. School management should be focused on a special attitude towards teachers from the perspective of McGregor's «Y» theory because innovations are being introduced at school and teachers need help in meeting new demands but not be left alone with their problems and immediate solutions to them.

It is necessary to organize a psychological service at the university to support to students and teachers. It is important to discuss current education questions with colleagues at the university. The management of departments should clearly divide the functional duties between teachers according to the position they occupy (assistant, senior teacher, associate professor, etc.), as the ratio of types of work for teachers in higher education changes, for example, the higher the occupied position the more research work the teacher has to do and the share of educational contact work decreases accordingly. Besides higher education teachers have to compete in contests for vacancy positions and the competition is rather hard because a refusal to participate or losing in it can provoke a dismissal. These situations can cause a lot of tension in the relationship between colleagues. It is the competent guidance and support of higher education teachers that can help them set priorities in their work and determine the vector of their professional development.

Anyway, the variety of measures to prevent the development of emotional burnout syndrome in higher and secondary education should be implemented as well as the emotional burnout monitoring among the secondary and higher education teachers. It is of vital importance to find the reasons of emotional burnout in each particular case and neutralize them by conducting psycho corrective work.

\section{References}

1. S.A. Vahabova, Emotional burnout of a teacher: symptoms, prevention measures, Colloquium-journal [online], 9(61) (2020)

2. M.A. Pisarevskaya, Teacher's emotional burnout and psychological wellbeing, World of Science. Pedagogy and psychology, [online], 4(7), (2019)

3. R. Bianchi, I.S. Schonfeld, P. Vandel, E. Laurent, On the Depressive Nature of the «Burn-out syndrome», A Clarification, European Psychiatry, 41, 109-110 (2017)

4. M.S. Carlotto, Sindrome de burnout e fatores associados: Um estudo epidemiológico com professores [Factors associated with burnout's syndrome, An epidemiological study of teachers], Universidade Luterana do Brasil, Canoas, Brazil Cad Saude Publica, 22, 1017-1026 (2017)

5. V.V. Sobol, Correction and prevention of burnout syndrome in the professional activity of teachers, Symbol of science, 1, 121-124 (2019)

6. T.P. Bartosh, O.P. Bartosh, M.V. Mychko, Research of the teachers' mental health features in the dynamics of the educatiobal process, Ecopsychological research-6: ecology of childhood and psychology of sustainable development, 6, 194-197 (2020)

7. G.V. Sorokoumova, O.V. Shurygina, Modern methods of diagnostics and psychological correction of teachers' emotional burnout, Perm University Herald. Series «Philosophy. Psychology. Sociology», 3, 437-443 (2017) 
8. V.G. Liashenko, Prevention of emotional burnout of teachers at a higher education institution, StudNet, 8, 66-72 (2020)

9. L.V. Magomedova, The syndrome of a teacher's emotional burnout and its influence on productive activity in group, Bulletin of Science and Education, 17(71), 96-98 (2019)

10. R.I. Sunnatova, Communicative skills and the teacher' emotional burnout in subjectsubject interaction with students, Society: sociology, psychology, pedagogy, 11(67), 94-101 (2019)

11. T.I. Dzhappueva, T.V. Tymoshenko, The study of teachers' emotional burnout level, Azimuth of Scientific Research: Pedagogy and Psychology, 2(15), 215-217 (2016)

12. T.P. Emelyanova, E.I. Shuraleva, Personal Factors of Emotional Burnout among Teachers in Correctional School, The horizons of the Humanities, 5, 67-84 (2018)

13. V.G. Belov, Y.A. Parfenov, S.A. Parfenov, N.L. Boyar, O.A. Titova, The forecast of teachers' emotional burnout development, Scientific Notes of the P.F. Lesgaft University, 3(157), 352-356 (2018)

14. E.A. Polishchuk, N.N. Krylova, Psychological and pedagogical research of teachers' emotional burnout syndrome, Bulletin of the Penza State University, 3(15), 20-25 (2016)

15. Yu.V. Vardanyan, A.A. Paramonov, Optimization of stress resistance of teachers with emerging emotional burnout, World of Science. Pedagogy and psychology, [online], 6(7), 24 (2019)

16. D.G. Saibulaeva, P.M. Kagirova, Features of «emotional burnout» syndrome's development among teachers, The world of science, culture, and education, 3(70), 368370 (2018)

17. O.A. Veselova, Professional motivation and the level of emotional burnout of teachers, Bulletin of Science and Education, 18(72), 96-98 (2019)

18. A.V. Dolgopolova, A.M. Manukhina, Psychological and pedagogical prevention of teachers' emotional burnout, Bulletin of the Samara State Technical University. Series «Psychological and pedagogical sciences», 2(46), 75-86 (2020)

19. F. Matveicheva, Prevention of teachers' emotional burnout, Achievements of science and education, 7(29) 103-104 (2018)

20. S. Leonova, Emotional burnout of secondary and higher education teachers: a comparative analysis, The development of social Sciences of the Russian students, 2 , 32-35 (2017) 